\title{
Sobrecarga Emocional ante a Malformação Congênita e o Enfrentamento de Cuidadoras
}

\section{Emotional Burden face to the Congenital Malformation and Coping of Caregivers Sobrecarga Emocional frente la Malformación Congénita y el Afrontamiento de Cuidadores}

\author{
Ana Cristina Barros da Cunha \\ Elora Correia Sales \\ Patricia Pinheiro da Silva \\ Universidade Federal do Rio de Janeiro (UFRJ) \\ Karolina Alves Albuquerque \\ Universidade Federal do Espírito Santo (UFES)
}

\begin{abstract}
Resumo
Casos de crianças com malformações congênitas aumentaram após a epidemia de infecção pelo vírus Zika, resultando em impacto e sobrecarga emocional para cuidadores. O objetivo deste estudo foi analisar a sobrecarga emocional e o enfrentamento da malformação congênita por cuidadoras parentais. Doze cuidadoras, pacientes da Maternidade-Escola da Universidade Federal do Rio de Janeiro (UFRJ), responderam aos instrumentos: Protocolo de Dados Gerais, Questionário "Momento da Notícia", Escala de Enfrentamento de Problemas e Escala de Impacto da Sobrecarga sobre Cuidadores (Zarit Burden Interview Scale). Estratégias de "Busca por práticas religiosas" e "Focadas no problema" foram as mais adotadas pelas cuidadoras, que apresentaram níveis de sobrecarga emocional leve a moderado. Conclui-se que a malformação congênita deve ser considerada como um importante estressor para a família.
\end{abstract}

Palavras-chave: malformação congênita, adaptação psicológica, cuidadores

\begin{abstract}
Cases of children with congenital malformations increased after the Zika virus epidemic, resulting in impact and emotional burden for caregivers. This study aimed to analyze the emotional burden and the coping face to congenital malformation by the parental caregivers. Twelve caregivers, patients from the Maternity School of the Universidade Federal do Rio de Janeiro (UFRJ), answered these instruments: General Data Protocol, Questionnaire "The Moment of News", Coping Strategies face to Problems Scale, and Zarit Burden Interview Scale for Caregivers. Strategies of "Searching for religious practices" and "Focused on the problem" were the most adopted by caregivers, who presented mild to moderate levels of emotional burden. The impact of congenital malformation on caregivers must be considered as an important stressor for the family.
\end{abstract}

Keywords: congenital malformation, psychological adaptation, caregivers

\section{Resumen}

Los casos de malformaciones congénitas aumentaron después de la epidemia de la infección del virus Zika, resultando en impacto y sobrecarga para los cuidadores. Este articulo tiene como objetivo analizar la sobrecarga emocional y el afrontamiento de cuidadores parentales frente a la malformación congénita. Doce cuidadoras, pacientes de la Maternidad Escuela de la Universidade Federal do Rio do Janeiro (UFRJ), respondieron los instrumentos: Protocolo de Datos Generales, Encuesta "Momento da la Noticia", Escala de Afrontamiento de Problemas, Escala de Impacto de la Sobrecarga sobre Cuidadores (Zarit Burden Interview). Las estrategias de "Búsqueda de prácticas religiosas" y "Centradas en el problema" fueron las más adoptadas por las cuidadoras, que presentaron niveles de sobrecarga emocional leve a moderado. Se concluye que la malformación congénita debe ser considerada como un factor estresante importante para la familia.

Palabras clave: anomalías congénitas, adaptación psicológica, cuidadores

\footnotetext{
${ }^{1}$ Endereço para contato: Instituto de Psicologia (UFRJ), Av. Pasteur, 250, Urca, Rio de Janeiro, RJ, CEP: 22290-240. E-mail: acbcunha@yahoo.com.br
} 


\section{Introdução}

Segundo a Organização Pan-Americana de Saúde (OPAS, 1984), as Malformações Congênitas (MC) se referem a qualquer defeito na constituição de um órgão ou conjunto de órgãos, causados por fatores genéticos, ambientais ou mistos, que resultam em uma anomalia morfológica, estrutural ou funcional, presente ou não desde o nascimento. Particularmente, as MC do Sistema Nervoso Central são aquelas decorrentes de problemas no fechamento do tubo neural, no prosencéfalo, no tronco cerebral e cerebelo, além de falhas na neurogênese, migração e diferenciação neuronais, sendo as formas de MC mais comuns a anencefalia, hidrocefalia, mielomeningocele e microcefalia (Pante et al., 2011).

A prevalência de recém-nascidos com alguma MC é de cerca de 3\% a 5\% no mundo (Amorim et al., 2006). No Brasil, as MC constituem a segunda causa de mortalidade infantil, sendo responsáveis por 11,2\% do total de mortes, segundo os indicadores do ano de 2010 do Ministério da Saúde (Brasil, 2010). Durante o período de 2000 a 2014, por exemplo, a média de casos de microcefalia notificados entre os nascidos vivos no Brasil foi de 164 ao ano. Ao longo deste período, houve certa constância nos números de notificações, embora, no ano de 2015, tenham sido registrados 1.608 novos casos (Brasil, 2017). Com isso, estratégias específicas em termos de políticas de saúde voltadas para essa população são previstas e necessárias (Pante et al., 2011), embora escassas mesmo em tempos de crise, como foi com o surto do vírus Zika, em 2015 (Tavelin, Cunha, Abel, \& Ribeiro, 2020).

Com o surto de infecção pelo vírus Zika com início em 2015 e pico de contágio em 2016, os casos de recém-nascidos com MC aumentaram, especialmente com microcefalia. Isso caracterizou uma epidemia de $\mathrm{MC}$ e resultou no planejamento e na adoção de medidas de políticas públicas para atenção à saúde desta população e prevenção dos agravos ao desenvolvimento destas crianças (Teixeira, Costa, Oliveira, Nunes, \& Rodrigues, 2016). De acordo com Tavelin et al. (2020), estas políticas públicas focam esforços em conter o avanço do surto de infecção de mulheres grávidas pelo vírus Zika e o aumento da incidência de microcefalia em recém-nascidos, além de outros desfechos, sem, entretanto, prestar a devida atenção às questões psicológicas que surgem. Para estes autores, a epidemia do vírus Zika pode ser vista ainda como um problema de gênero, porque fez com que as mulheres em idade fértil, as mais afetadas, vivenciassem um maior estado de insegurança na decisão por engravidar e no futuro do seu bebê.

Em face do crescimento de casos de MC pela epidemia do vírus Zika, que acometeu grande número de gestantes cujos bebês nasceram com microcefalia, considera-se relevante, social e cientificamente, investigar as repercussões emocionais deste problema para o binômio mãe-bebê. Destaca-se que nas políticas públicas brasileiras "o enfoque da atenção às gestantes com Zika se pautava na valorização dos aspectos físicos, em detrimento da análise das repercussões psíquicas e da atenção psicológica" (Tavelin et al., 2020, p. 233) durante a epidemia, mesmo que se reconhecesse que a mulher com diagnóstico do Zika vírus poderia vivenciar grande sofrimento psíquico pela perda de um filho idealizado como "normal".

É fato que o diagnóstico de uma MC tem impactos para os pais tanto quanto para a família. Estudos indicam que, ao receberem a notícia de MC, os pais costumam demonstrar sentimentos de choque, raiva, confusão, tristeza e culpa, além de ansiedade (Machado, 2012; Vicente et al., 2016; Félix \& Faria, 2018; Barata, Santos, Costa, Barbosa, \& Santos, 
2019). A descoberta de que o filho terá uma MC gera desorganização psíquica para os pais, que se veem diante da perda do filho idealizado e da necessidade de aceitação urgente de um filho real, muito diferente do que eles planejavam (Santos, Dias, Salimena, \& Bara, 2011; Silva, Girão, \& Cunha, 2016). A perda da perspectiva de normalidade do filho, somada ainda ao estigma da deficiência, gera a quebra nas expectativas de uma vida saudável para todos (Santos et al., 2011). Os pais sentem-se emocionalmente afetados, o que, algumas vezes, os levam à sensação de desamparo e incapacidade (Dias et al., 2019), seguida, por vezes, de crises conjugais que podem levar à separação do casal (Sá, Galindo, Dantas, \& Moura, 2020).

Diante da desorganização psíquica dos pais e da desestruturação familiar que a notícia de uma MC provoca, todos mudam severamente a sua rotina. Os pais passam a experimentar grande sobrecarga física, uma vez que a condição de malformação do filho exigirá deles lidar com demandas bem diferentes de uma criança típica. Consultas médicas, exames frequentes e atendimentos especializados passam a fazer parte da rotina familiar dos cuidadores principais daquele filho, por vezes exigindo longos e frequentes deslocamentos em busca de assistência, que nem sempre é realizada em uma mesma instituição (Roecker, Mai, Baggio, Mazzola, \& Marcon, 2012). Ser cuidador de alguém que depende totalmente do seu auxílio e que demanda demasiadamente dos seus cuidados gera ainda grande sobrecarga emocional. Pode ser comum os cuidadores vivenciarem sentimentos de desamparo, pela rotina solitária de manejo da condição do filho, somados à constante sensação de exaustão física pelas inúmeras responsabilidades que passam a assumir (Silva, Girão, \& Cunha, 2016). Tudo isso, agregado ao estigma da deficiência que os marcará para sempre, faz com que os cuidadores vivenciem grande sobrecarga emocional.

Estudos apontam que fatores como o apoio mútuo do casal, a presença de uma rede de suporte e o auxílio das instituições que prestam assistência e oferecem apoio à família podem ter repercussão positiva na percepção desta sobrecarga (Vicente et al., 2016; Boaventura, Borges, \& Ozaki, 2016). Para se adaptarem da melhor maneira possível a esta situação de sobrecarga, os cuidadores precisarão utilizar diferentes estratégias de enfrentamento (ou coping) para lidar com as demandas de cuidado e a desorganização psíquica que os afetam. Estratégias de coping, ou seja, recursos comportamentais e/ou cognitivos usados no enfrentamento de situações estressantes, são de grande importância, porque proporcionam aos cuidadores a modulação dessa experiência e, consequentemente, a manutenção do seu equilíbrio psíquico e o manejo das demandas físicas, emocionais e sociais (Benute, et al., 2011).

É com base em estratégias de enfrentamento que os cuidadores buscam resolver seus conflitos e manejar o estresse da situação, quer seja buscando informações para compreender melhor a condição do filho, quer seja à procura de conforto em pessoas ou instituições, como a religião, por exemplo, para compartilhar suas angústias. Os cuidadores podem, ainda, enfrentar a situação simplesmente negando e se esquivando de lidar resolutamente com as demandas da situação. Pesquisas sobre o enfrentamento da MC por cuidadores revelam que, em geral, os pais se sustentam na religiosidade para lidar com as demandas provenientes da situação (Vasconcelos \& Petean, 2009; Silva, Girão, \& Cunha, 2016; Nascimento et al., 2019). Estratégias de coping focalizadas no problema são recursos adotados também pelos cuidadores. Com este tipo de estratégia, o cuidador procura lidar com o impacto emocional provocado pelo diagnóstico de $\mathrm{MC}$ e enfrentar a situação buscando compreender 
racionalmente o problema de saúde da criança, o que, de acordo com Vasconcelos e Petean (2009), facilita a reelaboração dos significados simbólicos atribuídos à situação.

Diante do exposto, conclui-se que o nascimento de um filho com MC gera grande vulnerabilidade, física e psíquica, para seus cuidadores principais, bem como para todos os envolvidos que se veem marcados pelo estigma da deficiência da criança. Dessa forma, considerando que o diagnóstico da MC de uma criança resulta em impacto para seus cuidadores, este estudo teve como objetivo analisar a sobrecarga emocional e o enfrentamento da malformação congênita por cuidadoras parentais.

\section{Método}

Com base em delineamento descritivo e amostra de conveniência, a pesquisa foi realizada com 12 cuidadoras parentais principais, dez mães e duas avós, de crianças com Malformação Congênita (MC) neurológica (mielomeningocele, hidrocefalia e microcefalia) com idades entre 9 e 14 meses, acompanhadas pelo Serviço de follow-up do Setor de Neonatologia da Maternidade-Escola da UFRJ. Destaca-se que as duas avós foram incluídas no estudo porque eram as cuidadoras principais da criança, já que, em ambos os casos, a mãe abandonou o filho quando nasceu.

A duração total da coleta de dados da pesquisa foi de seis meses. Neste período, as cuidadoras eram convidadas a participar da pesquisa quando compareciam para a consulta naquele serviço. Após assinarem um Termo de Livre Consentimento Esclarecido, aprovado pelo Comitê de Ética da própria instituição (CAEE n. 06386412.1.0000.5275, de 6 de setembro de 2012), era feita uma entrevista individual com cerca de 30 minutos de duração, na qual elas respondiam aos seguintes instrumentos, nesta ordem: 1) um Protocolo de Dados Gerais, para investigar variáveis sociodemográficas (idade, estado civil, escolaridade, religião) e psicossociais (percepção de suporte familiar); 2) o Questionário "Momento da Notícia", para investigar aspectos relacionados ao momento do diagnóstico e recursos familiares para o enfrentamento atual da MC. Esclarece-se que esse questionário, com perguntas abertas e fechadas, foi proposto originalmente por Ramos, Hoffman e Regen (1985), com o objetivo de avaliar como a notícia da deficiência é comunicada, quais as primeiras reações dos pais e da família e as estratégias de enfrentamento utilizadas; 3) Escalas Modos de Enfrentamento de Problemas (EMEP) (Seidl, Trócoli, \& Zanon, 2001), para avaliar as estratégias de enfrentamento; e 4) Escala de Impacto da Sobrecarga sobre Cuidadores (Zarit Burden Interview [ZBI], Zarit, Orr, \& Zarit, 1985), para avaliar os níveis de sobrecarga emocional. Destaca-se que estes dois últimos instrumentos eram padronizados para avaliação em contextos de saúde.

A EMEP é um instrumento brasileiro padronizado usado para identificar as estratégias de enfrentamento ante o estressor saúde em uma escala de 45 itens, distribuídos em quatro fatores: 1) Enfrentamento focado no problema (18 itens), que inclui estratégias comportamentais de aproximação em relação ao estressor, para solucionar o problema, e esforços cognitivos voltados para a reavaliação do problema, percebendo-o como positivo; 2) Enfrentamento focado na emoção (15 itens), que inclui estratégias cognitivas ou comportamentais com função paliativa ou de afastamento do problema; 3) Enfrentamento focado na busca de práticas religiosas/pensamento fantasioso ( 7 itens), que inclui estratégias cognitivas ou comportamentais baseadas em pensamentos e comportamentos religiosos que 
são utilizados para o enfrentamento do problema; e 4) Enfrentamento focado na busca por suporte social (5 itens), que inclui estratégias cognitivas ou comportamentais de avaliação e procura por apoio instrumental, emocional ou de informação para enfrentar o problema. É uma escala do tipo Likert com alternativas de respostas distribuídas em uma escala de cinco pontos, que variam desde 1 = "eu nunca faço isso", até 5 = "eu faço isso sempre". No final do instrumento, há uma questão aberta que avalia se a pessoa utiliza alguma outra estratégia de enfrentamento que não esteja incluída na escala. A correção da escala se dá por meio da separação dos itens em quatro fatores, com uma soma desses itens que é dividida pelos valores estipulados para cada fator, alcançando-se uma pontuação máxima de 20 pontos e classificação feita por cálculo de medianas por fator. Esta escala tem sido usada para investigar o enfrentamento da sobrecarga emocional em cuidadores em contextos diversos de saúde (Mensorio, Kohlsdorf, \& Costa Junior, 2009; Cunha, Smith, Akerman, \& Souza, 2017) e também com pais de crianças com malformações (Vasconcelos \& Petean, 2009; Silva et al., 2016).

Para avaliação da percepção de sobrecarga emocional pelos cuidadores, foi usada a versão brasileira da Escala de Avaliação do Impacto da Sobrecarga sobre Cuidadores (Scazufca, 2002). Originalmente, a Zarit Burden Interview (ZBI) foi proposta como um instrumento padronizado para identificar indicadores de sobrecarga subjetiva em cuidadores no contexto de saúde (Zarit et al., 1985). É uma escala autoaplicável do tipo Likert composta por 22 itens com alternativas de respostas dispostas em uma escala de cinco pontos (sendo 0 = "nunca", até 4 = "sempre"). A versão utilizada, como no instrumento original, identifica indicadores de sobrecarga emocional com base em questões sobre as relações interpessoais, o bem-estar, a situação financeira do cuidador, entre outras. A classificação é feita pelo somatório de todos os itens, que variam de 0 a 88. Maiores pontuações correspondem a uma maior sobrecarga emocional, que pode ser classificada em: a) 0 a 20 pontos = ausência de sobrecarga; b) 21 a 40 pontos = sobrecarga leve a moderada; c) 41 a 60 = sobrecarga moderada a severa; e d) acima de 61 pontos = sobrecarga intensa. Esta escala tem sido usada para investigar a sobrecarga emocional em cuidadores no contexto de saúde (Boaventura et al., 2016; Luzardo, Gorini, \& Silva, 2006).

Os instrumentos padronizados foram corrigidos de acordo com suas próprias normas. 0 "Questionário Momento da Notícia", aplicado em entrevistas que foram gravadas e posteriormente transcritas, teve seu conteúdo analisado com base nas seguintes categoriais previamente estabelecidas: a) Percepção da comunicação do diagnóstico; b) Reação materna e familiar ante o diagnóstico; e c) Recursos de enfrentamento do diagnóstico.

Os dados quantitativos das escalas foram organizados em planilhas do Microsoft Excel para cálculos das medianas do grupo para cada uma das estratégias de enfrentamento obtidas pela EMEP. Estabeleceu-se a mediana como a medida mais adequada de mensuração para esta escala, uma vez que a distribuição dos dados da amostra foi não paramétrica. Foi analisada também a frequência de ocorrência dos níveis de sobrecarga emocional no grupo, obtidos pela Escala do Impacto da Sobrecarga sobre Cuidadores, verificada por meio do cálculo do número de ocorrências em que cada nível de sobrecarga foi apresentado. 


\section{Resultados}

Segundo o Protocolo de Dados Gerais, a média de idade das cuidadoras foi de 31 anos $(A V=21-59)$, e a maioria tinha ensino médio (completo: $n=07$; incompleto: $n=01$ ). Ensino fundamental (completo: $n=02$; incompleto: $n=01$ ) e superior (incompleto: $n=01$ ) também foram observados entre as cuidadoras. A maioria delas $(n=09)$ tinha companheiro e se encontrava em um relacionamento conjugal estável, com exceção das duas avós. Todas declararam ter alguma religião, e apenas uma declarou não ser praticante. Todas relataram receber também suporte familiar, e a maior parte delas $(n=09)$ se dedicava exclusivamente ao cuidado da criança, não exercendo atividades remuneradas.

Pelo Questionário "Momento da Notícia", foi possível observar que a comunicação do diagnóstico da MC foi feita por médicos em todos os casos e, na maioria das vezes $(n=10)$, percebida de maneira positiva, como ilustra esse relato de uma entrevistada: "Foi de uma forma gentil e cuidadosa" (E2). Apesar de as cuidadoras relatarem que a notícia do diagnóstico foi recebida de forma positiva, a reação posterior à notícia foi negativa para grande parte delas ( $n=11$ ) e, até mesmo, para uma das cuidadoras, a reação foi de indiferença: "Não mudou nada" (E4). Em sua maioria, as primeiras reações ante o diagnóstico de MC foram de tristeza, "Fiquei muito triste, chorei na hora" (E7); choque, "Choque, porque eu fiz tudo certo na gestação" (E3); e desespero, "Me senti impactada, abalada, meu mundo caiu" (E9); acompanhadas de preocupação e sentimentos de desvalia, "Me senti um nada, pois o médico disse que eu estava 'criando' um monstro" (E5).

Sobre a reação paterna, foi observado que, em geral, sete pais reagiram de maneira negativa, "Ficou chocado, chorou. Porque não era isso que estava nos planos" (E5), e os demais reagiram de maneira empática, "Reagiu tranquilamente e me encorajou" (E2). Algumas cuidadoras ( $n=05$ ) relataram, ainda, ter ocorrido mudanças no relacionamento conjugal depois da notícia do diagnóstico, tanto positivas $(n=02)$ quanto negativas $(n=03)$, sendo que, em um caso, isso resultou na separação do casal.

Pelo Questionário "Momento da Notícia", também pôde ser identificado que as cuidadoras se utilizavam de estratégias de enfrentamento não resolutivas ante o diagnóstico, como a negação. Duas delas relataram que apresentaram padrões de negação quando foram informadas sobre a deficiência da criança, como ilustra esse relato: "Demorou cair a ficha" (E3). Por sua vez, todas as cuidadoras declararam sentir necessidade de conversar com alguém sobre a situação, ainda que nem todas tenham contado com esse suporte. Para aquelas cuidadoras que contaram com suporte emocional para lidar com o diagnóstico de $M C$, a ajuda de familiares ( $n=03)$, ajuda da comunidade religiosa $(n=1)$ e ajuda de amigos $(n=4)$ foram as mais citadas. $O$ apoio de um psicólogo particular ( $n=2$ ) e o apoio do Serviço de Psicologia da Maternidade-Escola da UFRJ também foram considerados como importantes para o enfrentamento da situação.

Considerando ainda que o Questionário "Momento da Notícia" foi aplicado de forma retrospectiva, todas as cuidadoras relataram experimentar atualmente sentimentos positivos em relação à $\mathrm{MC}$, decorridos em média nove meses após o diagnóstico. Ressaltaram o aprendizado proporcionado por essa experiência ("Hoje estou mais tranquila e aprendi a lidar com isso"; E8), ainda que sentimentos negativos tenham sido experimentados no início.

Na Figura 1, é possível observar que as estratégias de enfrentamento "Focalizadas na busca de práticas religiosas/pensamento fantasioso" e "Focalizadas no problema" foram as mais 
prevalentes para o grupo, ainda que com valores de medianas muito próximas $(\mathrm{Md}=4,1$; $\mathrm{Md}=4$, respectivamente).

Figura 1. Medianas das Estratégias de Enfrentamento pela Escala Modos de Enfrentamento de Problema (EMEP).



Em relação aos dados de sobrecarga emocional obtidos pela Escala de Avaliação do Impacto da Sobrecarga por Cuidadores, a maior pontuação obtida foi de 37, e a mínima, 18. Tais pontuações revelaram que a maior parte das cuidadoras $(n=09)$ apresentava níveis leve a moderado de sobrecarga emocional $(A v=21-37)$. Pouca ou nenhuma sobrecarga foi observada somente para três cuidadoras ( $A v=18-19)$.

\section{Discussão}

É esperado que um diagnóstico de MC seja gerador de conflitos seguido de crise na vida pessoal e familiar, devido à desorganização social, econômica e psíquica que este evento ocasiona em todos os envolvidos no contexto de nascimento. Sentimentos de angústia, tristeza e desamparo são as primeiras experiências que surgem na dinâmica familiar e tem impacto particular para os cuidadores parentais principais. Estes podem ser os mais afetados pela situação, em face das demandas físicas, da sobrecarga emocional e da desorganização psíquica que vivenciam mais intensamente. Considerando isso, o objetivo deste estudo foi analisar a sobrecarga emocional e o enfrentamento da malformação congênita por cuidadores parentais.

Diante do crescimento dos casos de MC devido à epidemia de vírus Zika, especialmente nos anos de 2015, 2016 e 2017, estudos sobre o impacto que esta condição resulta nos cuidadores e na família de crianças acometidas têm relevância científica e social. A literatura científica já indica que um diagnóstico de MC gera impacto emocional com repercussões violentas e dramáticas nas expectativas do casal, que podem resultar em intensa angústia e sofrimento psíquico (Silva, Girão, \& Cunha, 2016; Machado, 2012). Logo, uma condição como 
a $\mathrm{MC}$ repercute na estrutura emocional da família, com consequências negativas, inclusive, para o relacionamento conjugal (Barros, Monteiro, Neves, \& Maciel, 2017). Tais repercussões não podem ser negligenciadas pelos profissionais de saúde e pesquisadores, especialmente em face do aumento de casos pela infecção do vírus Zika nos últimos anos (Tavelin et al., 2020). A epidemia do Zika deixou sequelas em longo prazo para a sociedade e famílias, sendo importante propor estudos que auxiliem a minimizar os impactos desta situação.

Neste estudo, optou-se por focar no contexto de cuidado da criança, discutindo-se as repercussões que a MC tem para os cuidadores parentais em termos da sobrecarga emocional e do enfrentamento deles da malformação em si e das suas consequências, desde a notícia do diagnóstico. A separação conjugal dos pais, inclusive com abandono da criança com malformação pela mãe e os cuidados parentais sendo assumidos por avós, é somente um dos aspectos que merece destaque. Isso não é incomum, já que muitos casais não se sentem capazes de lidarem juntos com a angústia provocada pela situação, que os fragiliza como pessoas e os distancia como casal. Para estes, o divórcio é uma resposta à crise que surge como um processo destrutivo (Machado, 2012; Sá, Galindo, Dantas, \& Moura, 2020). Não obstante, não se pode esquecer de que isso pode se relacionar também a questões conjugais anteriores e não diretamente associadas ao evento do diagnóstico. Contrariamente ao esperado, foi observado neste estudo que a maior parte dos pais reagiu de forma adaptativa ao impacto da notícia da MC, adotando, inclusive, atitudes empáticas para com suas parceiras. Essas reações positivas, inclusive de encorajamento da cuidadora, tranquilizando-a para lidar com a condição do filho, podem ser facilitadoras do enfrentamento deste momento. $O$ apoio mútuo entre o casal é capaz de promover mais união no processo de adaptação à situação (Félix \& Faria, 2018), fazendo com que ambos se recuperem do impacto do diagnóstico e, juntos, possam enfrentar a sobrecarga física e emocional com que precisarão lidar.

A percepção de suporte familiar e de um relacionamento estável com o companheiro, relatado pela maioria das cuidadoras, é outro ponto de destaque. De certo, isso sustenta o enfrentamento da MC por aquelas cuidadoras, especialmente para aquelas que a reação inicial do parceiro foi negativa. Possivelmente, esta reação do parceiro teve repercussão na percepção inicial da MC por aquelas cuidadoras que também reagiram de forma negativa ou minimamente indiferente. Sentimentos de tristeza, choque e desespero foram relatados na vivência inicial do diagnóstico, o que corrobora estudos que afirmam que a chegada de um bebê com malformação produz descontinuidade no processo de idealização do nascimento de um filho perfeito, com sonhos desmoronados e sentimentos negativos não só da mãe, mas também do cônjuge e de toda a família ampliada (Santos et al., 2011; Roecker et al., 2012). É importante não desconsiderar estas reações iniciais de tristeza, choque e desespero, comuns em cuidadores de crianças com deficiências (Gomes \& Piccinini, 2010; Machado, 2012; Vicente et al., 2016). Como observadas nas participantes deste estudo, estas reações não devem ser negadas ou negligenciadas pelos profissionais que atendem esta clientela, porque são sinais de como o impacto da MC está sendo elaborado simbolicamente e quais recursos de enfrentamento estão sendo adotados para lidar com a situação. Muito pelo contrário, observar que aqueles sentimentos eram acompanhados ainda por sentimentos de desvalia reforça a necessidade de prestar ainda mais atenção aos desfechos psíquicos que esta situação pode resultar.

Não obstante, o fato de a reação negativa inicial ante a $M C$ ter sido reelaborada com o 
tempo, dando lugar a uma percepção mais positiva da situação, baseada na interpretação, inclusive, de que essa experiência promoveu o aprendizado de uma lição existencial, revela que o impacto da MC passa por um processo lógico-temporal de ressignificação, que pode facilitar o enfrentamento e a readaptação à situação. Nossos achados sugerem que essa reação inicial negativa inaugurou, no seu devido tempo, a construção de novos laços afetivos com aquele filho, e que isto pode ter resultado na aceitação da perda da perspectiva de normalidade de toda uma família. Segundo Santos et al. (2011), esta será uma marca indelével de um estigma que toda a família carrega, para a qual precisará empreender esforços psíquicos para enfrentar e aceitar ativamente.

Sentimento de desamparo e a incapacidade para tomar atitudes podem também ser vivenciados perante a notícia do diagnóstico (Oliveira et al., 2019) e, certamente, relacionam-se com os recursos e as estratégias que as cuidadoras escolheram para enfrentar a sobrecarga emocional ante a MC. Embora estes sentimentos negativos possam ser elaborados e atenuados com o tempo, como já dito, eles estão presentes desde o início do processo de enfrentamento da deficiência. Com isso, os profissionais que prestam assistência à família, especialmente aqueles responsáveis por transmitir a notícia do diagnóstico, devem ter atenção aos sinais de sofrimento psíquico que acompanham o enfrentamento da situação. $\mathrm{Na}$ avaliação daquelas cuidadoras, o médico transmitiu a notícia do diagnóstico com carinho e cuidado profissional, com destaque para a qualidade dos esclarecimentos sobre a MC. Entretanto, houve também relatos de que a notícia foi transmitida de forma negativa, com uma postura de "ignorância" do profissional, gerando por vezes uma impressão de "terrorismo", sem melhores explicações e orientações sobre a condição do filho. Estudos sobre a comunicação médico-paciente afirmam que o momento e a forma como o diagnóstico é informado à família são aspectos relevantes que vão interferir no processo de adaptação familiar (Luisada, Fiamenghi-Jr, Carvalho, Assis-Madeira, \& Blascovi-Assis, 2015; Silva et al., 2016) e, por assim dizer, no enfrentamento da MC. Logo, a maneira como o diagnóstico é revelado interfere diretamente na forma como a situação será percebida e inicialmente enfrentada.

É incontestável que um diagnóstico de MC terá sempre um impacto gerador de estresse e angústia emocional para todos os envolvidos (Barros, Santos, Lima, Fonseca, \& Lovisi, 2013). Desta forma, as percepções ante o diagnóstico se associam à vivência subjetiva, presente e passada, das cuidadoras e terão impacto no cuidado que elas dispensarão à criança. Todos estes aspectos, pessoais e contextuais, imprimirão um contorno ao processo de enfrentamento e resposta da cuidadora às demandas físicas e psíquicas provocadas pela $\mathrm{MC}$, o que, por sua vez, repercutirá na percepção delas da sobrecarga emocional. Embora a maior parte das cuidadoras ( $n=09$ ) tenham apresentado níveis de sobrecarga emocional leve a moderada, também foram observados casos em que elas percebiam pouca ou nenhuma sobrecarga no cuidado da criança com MC. Podemos relacionar estes dados com o fato de que estas últimas contavam com algum tipo de suporte social, o que influenciou positivamente sua percepção da sobrecarga emocional (Misquiatti, Brito, Ferreira, \& Assumpção Júnior, 2015). Entretanto, isso é discutível, porque, segundo Misquiatti et al. (2015), existe ainda um certo receio por parte das cuidadoras em responder, clara ou verdadeiramente, sobre sua condição de cuidadora de um filho com MC.

Crenças e juízos de valor atribuídos a essa condição podem ser base de uma visão distorcida da percepção delas acerca da sua sobrecarga emocional. Igualmente, o fato de todas 
as participantes serem do sexo feminino pode ser um viés de análise neste estudo. Como se sentir sobrecarregada quando se é mulher em uma sociedade pautada em um modelo patriarcal, que impõe ao gênero feminino o estigma de ser a cuidadora da família? Pode-se pensar que a percepção da sobrecarga emocional resultante do nascimento de um filho com MC se mistura com a sobrecarrega que já pesa sob as mulheres como cuidadoras exclusivas dos filhos. De todo modo, segundo Pontes-Fernandes e Petean (2011), o impacto emocional de uma MC é indiscutível, ainda que muitas vezes não seja reconhecido e, muito menos, verbalizado. Considerando o mito do amor materno, que prevê que toda mãe deve amar seu filho de forma incondicional, deve ser difícil para aquelas cuidadoras admitirem que seu cuidado possa significar um peso ou uma sobrecarga em sua vida. Culturalmente, toda mãe deve nutrir esse amor incondicional pelo filho, ideia que pode ter estado subjacente às crenças daquelas cuidadoras, que se viam na obrigação de prestar um cuidado devotado e sem juízo de valor, independentemente da condição de nascimento da criança. Desse modo, a percepção de nenhuma ou pouca sobrecarga, assim como os níveis leves a moderados de sobrecarga emocional no desempenho de uma tarefa que, em si, é de grande sobrecarga, pode não corresponder à realidade daquelas cuidadoras, intimidadas em revelar como de fato se sentiam no cuidado do seu próprio filho.

Por sua vez, na análise do enfrentamento, predominaram as estratégias "Focalizadas na busca de práticas religiosas/pensamento fantasioso", o que quer dizer que as cuidadoras adotavam um tipo de coping muito frequente neste tipo de situação (Nascimento et al., 2019; Vicente et al., 2016), inclusive para pais (Silva, Girão, \& Cunha, 2016). O apego à religião pode contribuir na elaboração psíquica do diagnóstico e no manejo do estresse de cuidadoras de crianças com MC (Nascimento et al., 2019), mas também pode estar relacionado à percepção das cuidadoras de sua própria incapacidade de resolução da situação, para a qual não se tem cura e não há solução (Vicente et al., 2016). Importante discutir que este tipo de estratégia inclui recursos pautados ainda no uso de "pensamento fantasioso", o que sugeriria uma atitude defensiva ou de passividade das cuidadoras. Ainda que devido a limitações amostrais e metodológicas não tenha sido investigada a escolha das cuidadoras por este tipo de estratégia, é importante pontuar que um enfrentamento focado na "busca de práticas religiosas/pensamento fantasioso" inclui vários comportamentos e cognições que podem ser eficazes para o manejo do estresse, como a espiritualidade, por exemplo. A espiritualidade, que é muito presente na cultura brasileira, pode servir como fator de proteção se usada sob a perspectiva de um coping religioso positivo (Panzini, Maganha, Rocha, Bandeira, \& Fleck, 2011). Acredita-se, então, que o uso de estratégias de enfrentamento "Focalizadas na busca de práticas religiosas/pensamento fantasioso" pode ter sido eficiente para que aquelas cuidadoras lidassem com suas angústias ante a MC, tal como outros estudos já observaram (Vasconcelos \& Petean, 2009; Panzini et al., 2011; Nascimento et al., 2019).

A segunda estratégia de enfrentamento predominante foi a "Focalizada no problema", estratégia considerada como um recurso mais ativo e que promove um enfrentamento mais adaptativo à nova realidade (Souza \& Seidl, 2014). O fato de a maioria das cuidadoras ter ensino médio e, possivelmente, recursos acadêmicos e cognitivos para ajudá-las a compreender racionalmente a situação pode ter influenciado a escolha deste tipo de estratégia. Para lidar com o problema, as cuidadoras lançariam mão de buscas por conhecimentos sobre a MC, lendo para compreender mais e melhor sobre a condição do filho, por exemplo. 
Estratégias de enfrentamento como estas se fazem necessárias e são importantes, já que, por meio delas, as cuidadoras demonstram utilizar esforços resolutivos para minimizar as consequências negativas da situação (Vicente et al, 2016). Por sua vez, o uso deste tipo de coping pode ter influenciado a ocorrência dos baixos níveis de sobrecarga emocional, uma vez que o uso de recursos resolutivos para lidar com situações de permanente vulnerabilidade pode auxiliar no manejo do estresse e, consequentemente, da sobrecarga emocional. Situações estressoras como a MC de um filho atualizam o potencial de impacto emocional a cada momento do desenvolvimento da criança (como na entrada da vida escolar, por exemplo), gerando novas crises nas expectativas do casal, que convivem com um futuro incerto, repleto de barreiras que a criança deverá ultrapassar (Bulhões et al., 2020; Machado, 2012). Estas crises e incertezas sobre o futuro do filho são atualizadas ao longo do processo de enfrentamento, exigindo novos rearranjos e recursos de coping.

Ressalta-se que, no enfrentamento daquelas cuidadoras, as estratégias "Focalizadas na busca de suporte social" e "Focalizadas na emoção" foram as menos frequentes, sendo esta última a menos utilizada. O fato de as cuidadoras declararem ter suporte social e a familiaridade com as demandas do cuidado com aquele filho (pois a pesquisa ocorreu quase um ano após o diagnóstico) pode explicar esse achado. Para Mensorio et al. (2009), quando os cuidadores estão familiarizados com as diversas idas ao hospital, as possíveis internações ou a cansativa rotina que uma criança com MC, estariam mais preparados para a escolha de novas estratégias de enfrentamento para lidar com a vulnerabilidade biológica da criança.

Com efeito, todo diagnóstico de MC de um filho tem impacto na dinâmica psíquica, pessoal e familiar. É importante compreender como os cuidadores parentais percebem e enfrentam esta situação. Nossos achados auxiliam na compreensão de quais as estratégias e os recursos de enfrentamento (coping) as cuidadoras adotam para manejar o estresse e atenuar a sobrecarga emocional que a MC resulta. Ademais, em razão da relevância destes achados, precisamos ponderar as limitações e propor futuros estudos. Como dito, não é possível esclarecer se o tipo de coping mais adotado se focava, de fato, na religião ou em pensamentos fantasiosos, o que faria grande diferença para compreensão da resolutividade do enfrentamento daquelas cuidadoras. Por ser a EMEP uma escala padronizada, sua aplicação precisaria ser precedida de uma pergunta que permitisse qualificar o dado obtido e, assim, discriminar melhor se as cuidadoras usavam um coping religioso positivo ou negativo, por exemplo. Por fim, o tamanho e controle da amostra também é outra limitação do estudo, para a qual sugerimos a realização de novos estudos com maior número de participantes para ampliar estes achados, bem como contrapô-los ou complementá-los com outros resultados e novas discussões. Considerando que o cuidado parental repercute no desenvolvimento infantil, sugerimos, ainda, estudos que possam investigar o enfrentamento da $\mathrm{MC}$ em relação ao seu impacto para o desenvolvimento da criança. Estudos sobre o enfrentamento da MC relacionado à percepção da comunicação médica do diagnóstico, que incluam a investigação de variáveis psicossociais relacionadas ao momento da notícia do diagnóstico, podem também ser reveladores do quanto os profissionais envolvidos na assistência influenciariam na escolha das estratégias utilizadas pelos cuidadores. Somente compreendendo melhor esse enfrentamento será possível sensibilizar os profissionais de saúde para auxiliarem, efetivamente, no processo de enfrentamento de uma condição de vulnerabilidade psicossocial 
como a MC, que encerra a marca de um estigma que incide sob toda a família.

\section{Considerações Finais}

O diagnóstico de uma MC ocasiona grande desamparo nos cuidadores, em razão da angústia, dos sentimentos e das percepções negativas associados à situação. Tudo isso atravessa a construção da relação e do laço afetivos cuidador-criança desde precocemente, já que é possível identificar uma MC ainda dentro do útero materno por meio dos avanços tecnológicos que atualmente marcam o cenário da atenção à saúde materno-infantil. Dessa forma, é importante redobrar a atenção para a maneira como esse diagnóstico é transmitido, bem como investir em uma relação entre profissional de saúde e o cuidador-família baseada em laços de afeto e empatia.

Nossos resultados parecem apontar que, de fato, as primeiras reações ao diagnóstico marcam o início do processo de enfrentamento da $M C$, que será sempre permeado pela angústia e por sentimentos e reações negativas que lhe são próprios. Esta vivência negativa ante uma MC de um filho pode ser minimizada por estratégias de enfrentamento mais adaptativas que auxiliem cuidadores parentais e familiares a lidarem de forma mais adaptativa a sobrecarga emocional própria da situação. Fatores como uma rede social de apoio também têm influência importante e refletirão positivamente na percepção da sobrecarga emocional.

Assim, é fundamental que nos serviços de saúde os profissionais sejam sensibilizados para a necessidade e importância de adotarem uma postura ética e empática, que minimize a angústia e o sofrimento da família. Isto tudo refletirá no modo como esta situação é inicialmente percebida e será futuramente enfrentada por todos. Logo, indica-se que o cuidado com a MC deve extrapolar a atenção à saúde da criança e se voltar também para a saúde de quem cuida, no caso, o cuidador, para que esta rede de cuidados costurada por laços afetivos possa se manter o mais integra possível.

\section{Referências}

Amorim, M. M. R., Vilela, P. C., Santos, A. R. V. D., Lima, A. L. M. V., Melo, E. F. P., Bernardes, H. F. ... Guimarães, V. B. (2006). Impacto das malformações congênitas na mortalidade perinatal e neonatal em uma maternidade-escola do Recife. Revista Brasileira de Saúde Materno Infantil, 6(Suppl. 1), 19-25. doi:https://doi.org/10.1590/S1519-38292006000500003

Barata, A. L. S. R. B., Santos, J. S., Costa, J. M., Barbosa, L. N. F., \& Santos, E. P. (2019). Impacto da microcefalia no subsistema fraterno por meio do teste da família: Estudo de caso. Revista da SBPH, 22(1), 154-171. Recuperado de http://pepsic.bvsalud.org/scielo. php?script=sci_arttext\&pid=S151608582019000100009\&lng=pt\&tlng=pt

Barros, S. M. M., Monteiro, P. A. L., Neves, M. B., \& Maciel, G. T.S. (2017). Fortalecendo a rede de apoio de mães no contexto da síndrome congênita do vírus Zika: Relatos de uma intervenção psicossocial e sistêmica. Nova Perspectiva Sistêmica, 26(58), 38-59. Recuperado de http:// pepsic.bvsalud.org/scielo.php?script=sci_arttext\&pid=S0104-78412017000200004

Barros, V. C., Santos, J. F. C., Lima, L. A., Fonseca, D. L., \& Lovisi, M. L. (2013). Depressão e apoio social em gestantes de fetos com malformações atendidas em um hospital materno-infantil público de referência no Rio de Janeiro. Cadernos 
Saúde Coletiva, 21(4), 391-402. Recuperado de http://www.scielo.br/scielo. php?pid=S1414-462X2013000400006\&script=sci_abstract\&tlng=pt

Benute, G. R. G., Nonnenmacher, D., Evangelista, L. F. M., Lopes, L. M., Lucia, M. C. S., \& Zugaib, M. (2011). Cardiopatia fetal e estratégias de enfrentamento. Revista Brasileira de Ginecologia e Obstetrícia, 33(9), 227-233. Recuperado de http://www.scielo.br/pdf/rbgo/ v33n9/a02v33n9.pdf

Boaventura, L. C., Borges, H. C., \& Ozaki, A. H. (2016). Avaliação da sobrecarga do cuidador de pacientes neurológicos cadeirantes adultos. Ciência \& Saúde Coletiva, 21(10), 31933202. Recuperado de http://www.redalyc.org/pdf/630/63047756022.pdf

Brasil. (2010). Ministério da Saúde. Indicadores e dados básicos. DATASUS [homepage on the Internet]. Recuperado de http://www.datasus.gov.br/idb2010

Brasil. (2017). Ministério da Saúde. Secretaria de Vigilância em Saúde. Departamento de Vigilância de Doenças e Agravos Não Transmissíveis e Promoção da Saúde. Resumo executivo Saúde Brasil 2015/2016: Uma análise da situação de saúde e da epidemia pelo vírus Zika e por outras doenças transmitidas pelo Aedes aegypti. Brasília. DF: Ministério da Saúde. Recuperado de http://bvsms.saude.gov.br/bvs/publicacoes/resumo_saude_ brasil_2015_2016.pdf

Bulhões, C. S. G., Silva, J. B., Moraes, M. N., Reichert, A. P. S., Dias, M. D., \& Almeida, A. M. (2020). Repercussões psíquicas em mães de crianças com Síndrome Congênita do Zika Vírus. Escola Anna Nery, 24(2), e20190230. doi:https://doi.org/10.1590/2177-9465-ean-2019-0230

Cunha, A. C. B., Smith, J. A. B., Akerman, L. P. F., \& Souza, V. F. (2017). Discutindo sobre estresse e enfrentamento da prematuridade por cuidadores. Temas em Educação \& Saúde, 13(1), 41-58. Recuperado de http://seer.fclar.unesp.br/tes/article/viewFile/9605/6822

Dias, D. S. L., Silva, F. N., Santana, G. J., Santos, S. V., Santos, A. T., Silva, J. M, . . Alves, I. C. L. D. (2019). Paternidade e microcefalia por zika vírus: Sentimentos e percepções. Revista Enfermagem UFPE OnLine. 13(4), 1040-1045. Recuperado de https://pesquisa.bvsalud. org/portal/resource/pt/biblio-1021091

Félix, V. P. S. R, \& Faria, A. M. (2018). Microcefalia e dinâmica familiar: A percepção do pai frente à deficiência do filho. Cadernos de Saúde Pública, 34(12), e00220316. doi:https:// doi.org/10.1590/0102-311x00220316

Gomes, A. G., \& Piccinini, C. A. (2010). Malformação no bebê e maternidade: Aspectos teóricos e clínicos. Psicologia Clínica, 22(1), 15-38. Recuperado de http://www.scielo.br/ pdf/pc/v22n1/a02v22n1.pdf

Luisada, V., Fiamenghi-Jr, G. A., Carvalho, S. G., Assis-Madeira, E. A., \&Blascovi-Assis, S. M. (2015). Experiências de médicos ao comunicarem o diagnóstico da deficiência de bebês aos pais. Ciência \& Saúde, 8(3), 121-128. doi:http://dx.doi.org/10.15448/1983-652X.2015.3.21769

Luzardo, A. R., Gorini, M. I. P. C., \& Silva, A. P. S. S. (2006). Características de idosos com doença de Alzheimer e seus cuidadores: Uma série de casos em um serviço de neurogeriatria. Texto \& Contexto - Enfermagem, 15(4), 587-594. Recuperado de http://www.scielo.br/ scielo.php?pid=S010407072006000400006\&script=sci_abstract\&tlng=pt

Machado, M. E. C. (2012). Casais que recebem um diagnóstico de malformação fetal no pré-natal: Uma reflexão sobre a atuação do Psicólogo Hospitalar. Revista da SBPH, 15(2), 85-95. Recuperado de http://pepsic.bvsalud.org/scielo. php?script=sci_arttext\&pid=S151608582012000200007\&lng=pt\&tIng=pt 
Mensorio, M. S.; Kohlsdorf, M.; Costa Junior, Á. L. (2009). Cuidadores decriançase adolescentes com leucemia: análise de estratégias de enfrentamento. Psicologia em Revista, 15(1), 158-176. Recuperado de http://pepsic.bvsalud.org/pdf/per/v15n1/v15n1a10.pdf

Misquiatti, A. R. N., Brito, M. C., Ferreira, F. T. S., \& Assumpção Júnior, B. (2015). Sobrecarga familiar e crianças com transtornos do espectro do autismo: Perspectiva dos cuidadores. Revista CEFAC, 17(1), 192-200. Recuperado de http://www.redalyc.org/ pdf/1693/169338408022.pdf

Nascimento, I., Gomes, R., Vieira, S. N. S., Guedes, T. P., Santana, G. J., \& Silva, F. N. (2019). Vírus Zika e microcefalia: A mãe frente o diagnóstico do filho. Revista InterScientia, 7(1), 54-65. doi:https://doi.org/10.26843/interscientia.v7i1.918

Oliveira, P. S. de., Lamy, Z. C., Guimarães, C. N. M., Rodrigues, C. B., Silva, A. A. M. da., Simões, V. M. F., \& Sousa, P. S. (2019). Experiências de pais de crianças nascidas com microcefalia, no contexto da epidemia de Zika, a partir da comunicação do diagnóstico. Cadernos de Saúde Pública, 35(12), e00226618. doi:https://doi.org/10.1590/0102-311×00226618

Organização Pan-Americana de Saúde. (1984). Prevenção e controle de enfermidades genéticas e os defeitos congênitos: Relatório de um grupo de consulta. Washington (US): OPAS. Recuperado de http://www.scielo.br/scielo. php? script=sci_nlinks\&ref $=000074 \&$ pid $=S 14138123201200040001700002 \&$ lng $=p t$

Pante, F. R., Madi, J. M., Araújo, B. F., Zatti, H., Madi, S. R. C., \& Rombaldi, R. L. (2011). Malformações congênitas do sistema nervoso central: Prevalência e impacto perinatal. Revista da AMRIGS, 55(4): 339-344. Recuperado de http://amrigs.org.br/ revista/5504/0000072184miolo_AMRIGS4_art_original_malformaes_congnitas.pdf

Panzini, R. G., Maganha, C. R. N. S da., Bandeira, D. R., \& Fleck, M. P. (2011). Validação brasileira do Instrumento de Qualidade de Vida/espiritualidade, religião e crenças pessoais. Revista de Saúde Pública, 45(1), 153-165. doi:https://doi.org/10.1590/S0034-89102011000100018

Pontes-Fernandes, A. C., \& Petean, E. B. L. (2011). Sobrecarga Emocional e Qualidade de Vida em Mães de Crianças com Erros Inatos do Metabolismo. Psicologia: Teoria e Pesquisa, 27 (4), 459-465.

Ramos, T. C. L., Hoffmann, V. M. B., \& Regen, M. (1985). As dificuldades em transmitir a notícia: Pesquisa junto a pais de pacientes portadores de Síndrome de Down. Revista Brasileira de Deficiência Mental, 18, 47-69. doi:http://dx.doi.org/10.1590/S1413-81232010000200021 Roecker, S., Mai, L. D., Baggio, S. C., Mazzola, J. C., \& Marcon, S. S. (2012). A vivência de mães de bebês com malformação. Escola Anna Nery, 16(1), 17-26. Recuperado de http://www. scielo.br/scielo.php?script=sci_arttext\&pid=S1414-81452012000100003

Sá, S. A. A. G. de, Galindo, C. C., Dantas, R. S., \& Moura, J. C. de. (2020). Dinâmica familiar de criança com a síndrome congênita do Zika vírus no Município de Petrolina, Pernambuco, Brasil. Cadernos de Saúde Pública, 36(2), e00246518. doi:https://doi. org/10.1590/0102-311x00246518

Santos, S. R., Dias, I. M. Á. V., Salimena, A. M. O., \& Bara, V. M. F. (2011). A vivência dos pais de uma criança com malformações congênitas. Revista Mineira de Enfermagem, 15(4), 491-497. Recuperado de http://saudepublica.bvs.br/pesquisa/resource/pt/bde-22146

Scazufca, M. (2002). Brazilian version of the Burden Interview scale for the assessment of burden of care in careers of people with mental illnesses. Revista Brasileira de Psiquiatria, 24 (1), 12-17. doi:https://doi.org/10.1590/S1516-44462002000100006 
Seidl, E. M. F., Tróccoli, B. T., \& Zannon, C. M. L. C. (2001). Análise Fatorial de uma Medida de Estratégias de Enfrentamento. Psicologia: Teoria e Pesquisa, 17(3), 225-234. doi:https:// doi.org/10.1590/S0102-37722001000300004

Silva, E. H. P., Girão, E. R. C., \& Cunha, A. C. B. (2016). Enfrentamento do pai frente à malformação congênita do filho antes e depois do nascimento. Estudos e Pesquisas em Psicologia, 16(1), 180-199. Recuperado de http://pepsic.bvsalud.org/scielo. php?script=sci_arttext\&pid=S180842812016000100011\&lng=pt\&tIng=pt

Souza, J. R., \& Seidl, E. M. F. (2014). Distress e enfrentamento: Da teoria à prática em psicooncologia. Brasília Med, 50(3), 242-252. Recuperado de http://pesquisa.bvsalud.org/ controlecancer/resources/lil-702927

Tavelin, C. M., Cunha, A. C. B., Abel, R., \& Ribeiro, M. C. P: (2020). Atenção psicológica à gestante infectada por zika vírus: Revisão integrativa da literatura e das políticas públicas nacionais. Estudos Interdisciplinares em Psicologia, 11(1), 224-242. doi: https://doi. org/10.5433/2236-6407.2020v11n1p224

Teixeira, M. G., Costa, M. C., Oliveira, W. K., Nunes, M. L., \& Rodrigues L. C. (2016) The epidemic of zikavirus-related microcephaly in Brazil: Detection, control, etiology, and future scenarios. American Journal of Public Health, 106 (4): 601-5. doi:https://doi. org/10.2105/AJPH.2016.303113

Vasconcelos, L., \& Petean, E. B. L. (2009) O impacto da malformação fetal: Indicadores afetivos e estratégias de enfrentamento das gestantes. Psicologia, Saúde \& Doença, 10(1), 69-82. Recuperado de http://www.redalyc.org/pdf/362/36219059006.pdf

Vicente, S. R., Paula, K. M. P., Lopes, A. M., Muniz, S. A., Mancini, C. N., \& Trindade, Z. A. (2016). Emotional impact and maternal coping of congenital anomaly of babies in the NIC. Psicologia, Saúde \& Doenças, 17(3), 454-467. doi:https://doi.org/10.15309/16psd170312 Zarit, S. H., Orr, N. K., \& Zarit, J. M. (1985). The hidden victims of Alzheimer's disease: Families under stress. New York: New York University Press. Recuperado de http://www.scirp.org/ (S(351jmbntvnsjt1aadkposzje))/reference/ReferencesPapers.aspx?ReferenceID=1533464

Recebido em: 08/02/2018 última revisão: 27/03/2020

Sobre as autoras:

Aceite final: 15/05/2020

Ana Cristina Barros Cunha: PhD pela University of Miami, USA. Doutora em Psicologia Social e do Desenvolvimento pela Universidade Federal do Espírito Santo (UFES). Mestre em Educação Especial pela Universidade Estadual do Rio de Janeiro (UERJ). Professora titular da Universidade Federal do Rio de Janeiro (UFRJ). E-mail: acbcunha@yahoo.com.br, Orcid: https://orcid.org/0000-0003-0839-0130

Elora Correia Sales: Graduanda do Curso de Psicologia pela Universidade Federal do Rio de Janeiro (UFRJ). E-mail: elorasales@gmail.com, Orcid: https://orcid.org/0000-0003-0278-5684

Patricia Pinheiro da Silva: Bacharel em Psicologia pela Universidade Federal do Rio de Janeiro (UFRJ). Pesquisadora do Projeto Infância e Poluentes Ambientais (PIPA/UFRJ). E-mail: pinheiropps.pp@gmail.com, Orcid: https://orcid.org/0000-0002-1554-2828

Karolina Alves de Albuquerque: Doutora em Psicologia pela Universidade Federal do Espírito Santo (UFES). Mestre em Ciências da Reabilitação pela Universidade Federal de Minas Gerais (UFMG). Especialista em Terapia Ocupacional pela UFMG. Docente do curso de Terapia Ocupacional na UFES. E-mail: karol.arcos@gmail.com, Orcid: https://orcid.org/0000-0002-6044-3570 
